\title{
Interactions between Cocaine and the Putative Allosteric Dopamine Transporter Ligand SRI-31142
}

\author{
Megan J. Moerke, Subramaniam Ananthan, Matthew L. Banks, Jose M. Eltit, \\ Kelen C. Freitas, Amy R. Johnson, Surendra K. Saini, Tyler W. E. Steele, \\ and S. Stevens Negus
}

Departments of Pharmacology and Toxicology (M.J.M., M.L.B., K.C.F., A.R.J., S.S.N.) and Physiology and Biophysics (J.M.E., T.W.E.S.), Virginia Commonwealth University, Richmond, Virginia; and Chemistry Department, Drug Discovery Division, Southern Research, Birmingham, Alabama (S.A., S.K.S.)

Received May 29, 2018; accepted August 23, 2018

\begin{abstract}
Drugs that inhibit the dopamine (DA) transporter (DAT) include both therapeutic agents and abused drugs. Recent studies identified a novel series of putative allosteric DAT inhibitors, but the in vivo effects of these compounds are unknown. This study examined the abuse-related behavioral and neurochemical effects produced in rats by SRI-31142 [2-(7-methylimidazo[1,2-a]pyridin-6yl)-N-(2-phenyl-2-(pyridin-4-yl)ethyl)quinazolin-4-amine], one compound from this series. In behavioral studies, intracranial self-stimulation (ICSS) was used to compare the effects produced by SRI-31142, the abused and nonselective DAT inhibitor cocaine, and the selective DAT inhibitor GBR-12935 [1-[2(diphenylmethoxy)ethyl]-4-(3-phenylpropyl)piperazine]. In neurochemical studies, in vivo microdialysis was used to compare the effects of SRI-31142 and cocaine on levels of DA and serotonin in nucleus accumbens (NAc). The effects of SRI-31142
\end{abstract}

in combination with cocaine were also examined in both procedures. In contrast to cocaine and GBR-12935, SRI-31142 failed to produce abuse-related increases in ICSS or NAc DA; instead, SRI-31142 only decreased ICSS and NAc DA at a dose that was also sufficient to block cocaine-induced increases in ICSS and NAC DA. Pharmacokinetic studies suggested low but adequate brain penetration of SRI-31142, in vitro binding studies failed to identify likely non-DAT targets, and in vitro functional assays failed to confirm DA uptake inhibition in an assay of DAT-mediated fluorescent signals in live cells. These results indicate that SRI-31142 does not produce cocaine-like abuserelated effects in rats. SRI-31142 may have utility to block cocaine effects and may warrant further study as a candidate pharmacotherapy; however, the role of DAT in mediating these effects is unclear, and side effects may be a limiting factor.

\section{Introduction}

Dopamine (DA) transporter (DAT) inhibitors constitute a class of drugs that produce behavioral effects by binding DAT to block DA uptake and increase extracellular DA levels. This pharmacological class includes therapeutic agents, abused drugs, and experimental compounds, and these drugs can function either as selective DAT inhibitors [e.g., GBR-12935 (1-[2-(diphenylmethoxy)ethyl]-4-(3-phenylpropyl)piperazine)] or as nonselective inhibitors of multiple monoamine transporters (e.g., cocaine) (Matecka et al., 1996). Recently, a new type of DAT inhibitor was identified that differs from

This work was supported by the National Institutes of Health National Institute on Drug Abuse [Grant R33-DA029962] (to S.A.) and [Grant R01DA033930] (to J.M.E. and S.S.N.). Receptor binding profiles were provided by the National Institute of Mental Health (NIMH) Psychoactive Drug Screening Program (PDSP) [Contract \#HHSN-271-2013-00017-C] (NIMH PDSP, directed by Bryan L. Roth at the University of North Carolina at Chapel Hill, and Project Officer Jamie Driscol at NIMH, Bethesda, MD).

https://doi.org/10.1124/jpet.118.250902. prototype DAT inhibitors in three ways (Pariser et al., 2008; Rothman et al., 2015). Specifically, prototype DAT inhibitors like cocaine and GBR-12935 have similar potencies and high efficacies to block 1) extracellular-to-intracellular monoamine transport (i.e., monoamine uptake), 2) intracellular-toextracellular monoamine transport (i.e., amphetamine-induced monoamine efflux), and 3) binding to the DAT orthosteric binding-site labelled by radioligands such as $\left[{ }^{3} \mathrm{H}\right] \mathrm{WIN} 35428$. In contrast, the novel compounds have 1) high potency but only partial efficacy to block monoamine uptake, 2) little or no potency/efficacy to block amphetamine-induced monoamine efflux, and 3) very low potency to displace $\left[{ }^{3} \mathrm{H}\right]$ WIN35428. These findings have been interpreted to suggest that these novel compounds inhibit DAT by occupying a nonorthosteric (i.e., allosteric) binding site and may be useful as probes for transporter function or as novel therapeutic agents. However, the behavioral effects of these novel compounds relative to existing DAT inhibitors are unknown.

ABBREVIATIONS: ANOVA, analysis of variance; $\mathrm{APP}^{+}, 4$-(4-(dimethylamino)phenyl)-1-methylpyridinium; DA, dopamine; DAT, dopamine transporter; DMSO, dimethylsulfoxide; GBR-12935, 1-[2-(diphenylmethoxy)ethyl]-4-(3-phenylpropyl)piperazine; 5-HT, serotonin; ICSS, intracranial self-stimulation; $K_{\mathrm{i}}$, inhibitor constant; MCR, maximum control rate; NAc, nucleus accumbens; NET, norepinephrine transporter; PDSP, Psychoactive Drug Screening Program; SERT, serotonin transporter; SRI-31142, 2-(7-methylimidazo[1,2-a]pyridin-6-yl)-N-(2-phenyl-2-(pyridin-4yl)ethyl)quinazolin-4-amine; $T_{\max }$, time at $C_{\max } ;\left[{ }^{3} \mathrm{H}\right] \mathrm{WIN} 35428,(-)-2-\beta$-carbomethoxy-3- $\beta$-(4-fluorophenyl)tropane. 
The goal of this study was to evaluate the abuse-related behavioral and neurochemical effects produced in rats by SRI-31142 [2-(7-methylimidazo[1,2-a]pyridin-6-yl)-N-(2-phenyl2-(pyridin-4-yl)ethyl)quinazolin-4-amine] (Fig. 1), one compound from this new class of putative allosteric DAT inhibitors (Rothman et al., 2015). Similar to other compounds in this series, SRI-31142 has nanomolar potency but only partial efficacy to block monoamine uptake via all three transporters [i.e., DAT; serotonin (5-HT) transporter (SERT); norepinephrine transporter (NET)] in rat brain synaptosomes, 1000-fold weaker potency to block $\left[{ }^{3} \mathrm{H}\right]$ WIN35428 DAT binding, and no efficacy to block amphetamine-induced DAT-mediated monoamine efflux. The behavioral effects of SRI-31142 administered alone or in combination with cocaine were evaluated using intracranial self-stimulation (ICSS) in rats, and GBR12935 was included as a positive control. ICSS is one procedure that can be used in preclinical assessment of abuse potential (Wise, 1996; Carlezon and Chartoff, 2007; Negus and Miller, 2014), and it has been used extensively to evaluate both the abuse-related effects of DAT ligands (Bauer et al., 2013; Bonano et al., 2014a; Solis et al., 2017; Battisti et al., 2018) and the effectiveness of candidate medications to reduce the abuse potential of abused DAT ligands like cocaine (Bauer et al., 2014; Bonano et al., 2014b; Johnson et al., 2018). In ICSS procedures, subjects equipped with microelectrodes targeting a brain reward area are trained to emit a response (e.g., a lever press) to receive pulses of electrical brain stimulation. Drugs of abuse generally increase (or "facilitate") low rates of ICSS responding maintained by low frequencies or amplitudes of brain stimulation, and the prevailing evidence indicates that effective treatments for cocaine abuse attenuate cocaine-induced ICSS facilitation. The neurochemical effects of SRI-31142 administered alone or in combination with cocaine were evaluated using in vivo microdialysis in rats to monitor drug effects on levels of DA and 5-HT in nucleus accumbens (NAc). Drugs that facilitate ICSS generally increase the levels of DA in NAc, whereas drugs with little or no abuse potential do not affect or decrease NAc DA levels but may increase 5-HT (Di Chiara and Imperato, 1988; Czoty et al., 2002; Rothman and Baumann, 2006; Suyama et al., 2016). In particular, cocaine is well established to increase both NAc DA and 5-HT levels, and effective treatments for cocaine abuse attenuate cocaine-induced increases in NAc DA levels (Baumann et al., 1994; Johnson et al., 2018). We hypothesized that SRI-31142 would produce a cocaine-like increase in ICSS and in NAc DA and 5-HT by virtue of its high potency to block DAT- and SERT-mediated monoamine uptake in rat brain synaptosomes, and we further hypothesized that SRI-31142 would fail to block cocaine effects on these endpoints because SRI-31142 has very low potency to occupy the cocaine binding site on the DAT (Rothman et al., 2015).

As will be described below, our results did not support these hypotheses. Accordingly, SRI-31142 pharmacokinetics in rats were assessed to evaluate the adequacy of brain penetration. Additional studies on SRI-31142 pharmacodynamics were also conducted to examine possible off-target binding sites (Besnard et al., 2012) and the effects on DAT-mediated $\mathrm{Ca}^{2+}$ fluorescence and $\mathrm{APP}^{+}$uptake in live cells (Solis et al., 2017; Battisti et al., 2018). Overall, our results suggest that SRI31142 does not produce abuse-related behavioral or neurochemical effects and that it attenuates cocaine effects by acting via a non-DAT mechanism of action.

\section{Materials and Methods}

\section{Subjects}

Adult male Sprague-Dawley rats were used for all in vivo studies. Rats in ICSS and microdialysis studies were obtained from Envigo (Indianapolis, IN), weighed 310-350 g at the time of surgery, and were individually housed and maintained on a 12-hour light/dark cycle with lights on from 6:00 AM to 6:00 PM at Virginia Commonwealth University. Rats in pharmacokinetic studies were obtained from Charles River Labs International Inc. (Raleigh, NC), weighed approximately $250 \mathrm{~g}$ at the time of study, and were group housed on a 12-hour light/dark cycle with lights on from 6:00 AM to 6:00 PM at Southern Research (Birmingham, AL). All rats had free access to food and water except during testing. Animal maintenance and research were in compliance with National Institutes of Health guidelines, and all animal use protocols were approved by the respective Institutional Animal Care and Use Committees.

\section{Surgery}

Subjects in ICSS and microdialysis studies were anesthetized with isoflurane gas (3\%-4\% in oxygen; Webster Veterinary, Phoenix, AZ) until unresponsive to toe pinch and were placed in a stereotaxic apparatus (Kopf Instruments, Tujunga, CA). For ICSS studies, the cathode of a stainless steel electrode $(0.25 \mathrm{~mm}$ diameter and insulated except at the flattened tip; MS303/1-AIU/SPC; Plastics One Inc., Roanoke, VA) was implanted in the medial forebrain bundle at the<smiles>Cc1cc2nccn2cc1-c1nc(NCC(c2ccccc2)c2ccncc2)c2ccccc2n1</smiles><smiles>c1ccc(CCCN2CCN(CCOC(c3ccccc3)c3ccccc3)CC2)cc1</smiles>

GBR-12935<smiles>COC(=O)C1C(OC(=O)c2ccccc2)CC2CCC1N2C</smiles>

Fig. 1. Structures for SRI-31142, GBR-12935, and cocaine. 
level of the lateral hypothalamus $(2.8 \mathrm{~mm}$ posterior to bregma, $1.7 \mathrm{~mm}$ lateral to the midsagittal suture, and $8.8 \mathrm{~mm}$ ventral to the skull). For microdialysis studies, guide cannulae $(0.5 \mathrm{~mm}$ outer diameter; CXG-8; Amuza Neuroscience, San Diego, CA) were implanted bilaterally and terminated $1 \mathrm{~mm}$ above the NAc $(1.5 \mathrm{~mm}$ anterior to bregma, $1.8 \mathrm{~mm}$ lateral to midsagittal suture, and $6.0 \mathrm{~mm}$ ventral to dura). A dummy cannula (CXD-8; Amuza Neuroscience) was inserted into each guide cannula to maintain cannula patency. Electrodes and guide cannulae were secured to the skull using screws (Plastics One Inc.) and orthodontic resin (Butler Schein, Dublin, OH), and for ICSS studies the anode of the electrode $(0.125 \mathrm{~mm}$ diameter, uninsulated) was wrapped around one of the screws to act as a ground. Animals were allowed at least 7 recovery days prior to the initiation of ICSS training or microdialysis testing.

\section{ICSS}

Experiments were conducted in sound attenuating chambers that contained modular acrylic test chambers $(29.2 \times 30.5 \times 24.1 \mathrm{~cm})$ equipped with a response lever $(4.5 \mathrm{~cm}$ wide, extended $2.0 \mathrm{~cm}$ through the center of one wall, $3 \mathrm{~cm}$ off the floor), stimulus lights (three lights colored red, yellow, and green positioned $7.6 \mathrm{~cm}$ directly above the lever), a 2-W white house light, and an ICSS stimulator (Med Associates, St. Albans, VT). Electrodes were connected to the stimulator via bipolar cables and a commutator (Model SL2C; Plastics One Inc.). A computer and software program (Med Associates) controlled the stimulator, programming parameters, and data collection.

Rats were trained 5 days a week under a fixed-ratio 1 schedule of brain stimulation using procedures similar to those described previously for studies of other drugs acting at monoamine transporters (Bauer et al., 2013; Rosenberg et al., 2013; Bonano et al., 2014a; Solis et al., 2017). Each lever press resulted in the delivery of a 0.5 -second train of square-wave cathodal pulses (0.1-millisecond pulse duration), and stimulation was accompanied by illumination of the stimulus lights above the lever. Responses during the 0.5-second stimulation period did not result in additional stimulation. During the initial phase of training, sessions lasted 30-60 minutes, the frequency of stimulation was held constant at $158 \mathrm{~Hz}$, and the stimulation intensity was adjusted to the lowest value that would sustain responding for at least 30 stimulations per minute. Frequency manipulations were then introduced during sessions that consisted of sequential 10-minute components. During each component, a descending series of 10 current frequencies (158-56 Hz in 0.05 log increments) was presented, with a 60 -second trial at each frequency. A frequency trial began with a 5-second time-out followed by a 5-second "priming" phase, during which five noncontingent stimulations were delivered at a rate of one per second. This noncontingent stimulation was followed by a 50 -second "response" phase, during which responding produced electrical stimulation under a fixedratio 1 schedule. Training continued with 3-12 sequential components per day, and the current intensity was adjusted until rats reliably responded during the first three to four frequency trials of all components for at least 3 consecutive days. This intensity (range, 100-265 $\mu \mathrm{A}$ ) was held constant for the remainder of the study.

Once training was completed, ICSS testing began. Three sets of experiments were conducted in different groups of rats. First, the potency and time course of effects produced by the selective DAT inhibitor GBR-12935 were determined $(n=6)$. Dose-effect test sessions consisted of three sequential baseline components followed first by a 10-minute pretreatment interval during which animals were returned to their home cage and then by three sequential test components. Vehicle or a dose of GBR-12935 (1-10 mg/kg, i.p.) was administered at the start of the pretreatment interval, and dose order was randomized across rats using a Latin Square design. The timecourse test session consisted of three baseline components followed by intraperitoneal injection of $10 \mathrm{mg} / \mathrm{kg}$ GBR-12935, and then by pairs of test components beginning after 10,30,100, and 300 minutes.

A second set of rats $(n=8)$ was used to determine the potency and time course of effects produced by SRI-31142 using procedures identical to those used for GBR-12935. The effects of vehicle and 1-10 mg/kg, i.p., SRI-31142 were examined in dose-effect studies in five rats, and dose order was randomized across rats using a Latin Square design. A dose of $10 \mathrm{mg} / \mathrm{kg}$ SRI-31142 was tested in the timecourse study in six rats. A dose of $10 \mathrm{mg} / \mathrm{kg}$, i.p., cocaine was also tested as a positive control in seven rats. For this study, cocaine was dissolved in the same vehicle as SRI-31142 (DMSO/saline, 6:4).

A third set of rats $(n=7)$ was used to determine the effects of cocaine after pretreatment with SRI-31142. For these studies, test sessions consisted of three sequential baseline components, followed by the administration of vehicle or SRI-31142 (1-10 mg/kg, i.p.). Fifteen to twenty minutes after this first injection, $10 \mathrm{mg} / \mathrm{kg}$ cocaine in saline vehicle was administered intraperitoneally, and a pair of test components began 10 minutes later. Doses of SRI-31142 were randomized across rats using a Latin Square design. For rats in all three groups, two test sessions were typically conducted each week, with test sessions on Tuesdays and Fridays, and training days during which rats responded for brain stimulation during a three-component training session on Mondays, Wednesdays, and Thursdays.

The first baseline component of each session was considered an acclimation component, and the data were discarded. The primary dependent variable for all remaining components was the reinforcement rate in stimulations per trial during each frequency trial. To normalize these raw data, reinforcement rates from each trial in each rat were converted to the percentage maximum control rate (MCR), which was defined as the mean of the maximal rates observed during the second and third "baseline" components for that rat on that day. Thus, \% MCR $=[($ rate during a frequency trial $) /(\mathrm{MCR})] \times 100$. Normalized ICSS rates at each frequency were averaged across test components within each rat and then across rats to yield a "frequencyrate" curve for each experimental manipulation. Two-way ANOVA was used to compare frequency-rate curves, with ICSS frequency as one variable and dose or time as the second variable. A significant ANOVA was followed by a Holm-Sidak post hoc test, and the criterion for significance was set at $P<0.05$.

An additional summary measure of ICSS performance was calculated to collapse data across the independent variable of brain stimulation frequency and to highlight the effects of the independent variables of dose and time. To calculate this summary measure, the total number of stimulations per component delivered across all 10 frequency trials was determined for each component. Data were expressed as a percentage of the total stimulations per component earned during the daily baseline. Thus, \% baseline total stimulations was calculated as (mean total stimulations during test components/ mean total stimulations during baseline components $) \times 100$.

\section{Microdialysis}

Microdialysis procedures were similar to those described previously for studies of other drugs acting at monoamine transporters (Suyama et al., 2016; Johnson et al., 2018). On test days, rats were first anesthetized with $3.0 \%$ isoflurane in oxygen so that one of the dummy cannulae could be removed and replaced with a microdialysis probe (10 mm long; CX-I-8-2; Amuza Neuroscience). The microdialysis probes had a $2 \mathrm{~mm}$ tip composed of an artificial cellulose "cuprophan" membrane (50-kDa molecular weight cutoff) that extended beyond the $8 \mathrm{~mm}$ guide cannula and into the NAc. The probe was connected to a two-channel liquid swivel (TCS2-23; Amuza Neuroscience) and perfused with artificial cerebrospinal fluid ( $147 \mathrm{mM} \mathrm{NaCl}, 2.8 \mathrm{mM} \mathrm{KCl}$, $1.2 \mathrm{mM} \mathrm{CaCl}_{2}, 1.2 \mathrm{mM} \mathrm{MgCl}_{2}$ ) at a rate of $1 \mu \mathrm{l} / \mathrm{min}$. The rat was then placed into a square acrylic experimental chamber $\left(30 \mathrm{~cm}^{2}\right.$ floor space, $36 \mathrm{~cm}$ high). The mobile phase consisted of $1.5 \%$ methanol (EMD, Gibbstown, NJ), $100 \mathrm{mM}$ phosphate buffer (Sigma-Aldrich, St. Louis, $\mathrm{MO}$ ), $500 \mathrm{mg} / \mathrm{l}$ 1-decane sodium sulfonate (TCI America, Montgomeryville, $\mathrm{PA}$ ), and $50 \mathrm{mg} / \mathrm{l}$ EDTA-2Na ${ }^{+}$(Dojindo Laboratories, Kumamoto, Japan). Dialysate samples were collected into a 50- $\mu$ l injector loop at 10-minute intervals using an on-line auto-injector (EAS-20s; Amuza Neuroscience) and immediately analyzed for DA and 5-HT 
concentrations by high-performance liquid chromatography coupled to electrochemical detection (HTEC-500; Amuza Neuroscience).

DA and 5-HT were separated using a C18 reverse-phase column (PP-ODS II; Amuza Neuroscience) and detected using a graphite working electrode and an $\mathrm{Ag}$ versus $\mathrm{AgCl}$ reference electrode with an applied potential of $+450 \mathrm{mV}$. DA and $5-\mathrm{HT}$ were identified by characteristic standard solution retention times, and concentrations were quantified by comparison with peak heights of the standard concentration curve $(0.01-100 \mathrm{pg} / 10 \mu \mathrm{l})$ generated prior to drug administration in each microdialysis experiment. The lower neurotransmitter detection limit was $0.1 \mathrm{pg}$. DA and 5-HT levels were determined to be stable after six consecutive baseline samples were obtained with $<25 \%$ variability around the running mean of both neurotransmitters. For single-drug experiments, once DA and 5-HT levels stabilized, rats were injected intraperitoneally with vehicle, $10 \mathrm{mg} / \mathrm{kg}$ cocaine, or $10 \mathrm{mg} / \mathrm{kg}$ SRI-31142. To test the effects of SRI31142 as a pretreatment to cocaine, DA and 5-HT levels were allowed to stabilize, and rats were injected intraperitoneally first with $10 \mathrm{mg} / \mathrm{kg}$ SRI-31142 and then 20 minutes later with $10 \mathrm{mg} / \mathrm{kg}$ cocaine. Both SRI-31142 and cocaine were dissolved in a 6:4 ratio in DMSO/ saline vehicle for microdialysis studies, and the 6:4 DMSO/saline solution was also used for vehicle injections.

Each of the four treatment conditions included a sample size of five rats, and a total of 12 rats was used for the study. Each individual rat was tested no more than four times (no more than twice per cannula; at least 2 weeks between reaccessing a given site). At the completion of all experiments, rats were euthanized with carbon dioxide, and brains were removed and stored in $10 \%$ formalin. Probe placement was verified by visual inspection of cannula tracks in unstained brain sections as described previously (Suyama et al., 2016; Johnson et al., 2018). All rats had correct probe placements and were included in data analyses.

The primary dependent variables were extracellular DA and 5-HT concentrations in each dialysate fraction expressed as a percentage of the average of the six mean baseline concentrations before drug or vehicle administration for each experiment. The individual normalized DA and 5-HT concentrations were then averaged across rats to yield group mean results for graphical presentation. Results were analyzed by two-way ANOVA, with time and treatment as the two factors. Separate two-way ANOVAs were conducted to compare the effects of vehicle versus $10 \mathrm{mg} / \mathrm{kg}$ SRI-31142 on DA or 5 -HT changes and to compare the effects of $10 \mathrm{mg} / \mathrm{kg}$ cocaine versus $10 \mathrm{mg} / \mathrm{kg}$ SRI-31142 $+10 \mathrm{mg} / \mathrm{kg}$ cocaine on DA or 5 -HT changes. A significant interaction was followed by a Sidak post hoc test. The criterion for statistical significance was set at $P<0.05$. Raw baseline DA and 5-HT levels were compared between groups and analyzed by one-way ANOVA.

\section{Pharmacokinetic Studies}

SRI-31142 (10 mg/kg, i.p.), formulated in DMSO/saline in a 6:4 ratio, was administered to 15 rats. Blood and brain collection occurred at $0.167,0.5,1.67,5$, and 24 hours ( $n=3 /$ time point) after drug injection. At the designated time, rats were initially anesthetized by the inhalation of $5 \%$ carbon dioxide in oxygen, and 1.0-ml blood samples were collected from the retro-orbital plexus directly into tubes containing EDTA and centrifuged for plasma collection. Animals were then euthanized by inhalation of $100 \%$ carbon dioxide, and whole brains, including residual blood in cerebrovasculature, were collected, weighed, placed in tubes containing $2.8-\mathrm{mm}$ zirconium oxide beads, and homogenized in Dulbecco's phosphate-buffered saline $(4 \mathrm{ml} / \mathrm{g}$ brain). The resulting plasma and brain samples were analyzed for levels of unchanged compound using high-performance liquid chromatography tandem mass spectrometry method. The sensitivity for drug level determination was at least $0.5 \mathrm{ng} / \mathrm{ml}$ for plasma and at least $2.5 \mathrm{ng} / \mathrm{g}$ for brain. Pharmacokinetic parameters were calculated from mean drug concentrations versus time data using Phoenix WinNonlin version 6.3 [Pharsight (a Certara company), Cary,
NC]. Pharmacokinetic parameters were estimated from noncompartmental analysis of the data using WinNonlin Model 200 (for extravascular administration); a uniform weighting factor was applied to each data set. $T_{\max }$ and $C_{\max }$ values were determined directly from the data. Area under the curve values were calculated using the linear up/log down trapezoidal rule. The half-life was calculated from the first-order rate constant associated with the observed terminal portion of the plasma drug concentration versus time curve, as estimated by regression analysis, using a minimum of three nonzero time points after $\mathrm{T}_{\max }$. The regression with the largest $R^{2}$ adjusted (square of the correlation coefficient) value was selected as the best fit.

\section{Receptor Binding Screen}

SRI-31142 binding was assessed at 45 receptor targets using the Psychoactive Drug Screening Program (PDSP) (Besnard et al., 2012). The targets are listed in Table 2, and detailed assay protocols are available at the National Institute of Mental Health-PDSP web site (https://pdspdb.unc.edu/pdspWeb/).

\section{DAT Activity Measured Using Live Cell Imaging}

The stable cell line expressing the human DAT was developed previously using the FlpIn-TRex System (Thermo Fisher Scientific, Waltham, MA) (Cameron et al., 2015). Cells were plated in 96-well flat-bottom imaging plates and, to transiently express the voltagegated $\mathrm{Ca}^{2+}$ channel, cells were cotransfected with plasmids coding $\alpha_{1 \mathrm{C}}, \beta_{3}, \alpha_{2} \delta$, and enhanced green fluorescent protein using FuGENE 6 (Promega, Madison, WI) in a ratio of 0.8:0.5:0.75:0.25 (in micrograms), respectively. For $\mathrm{APP}^{+}$uptake studies, cells were transfected with a red fluorescent protein (DsRed, TaKaRa Bio USA, Mountain View, CA) coding plasmid to enable cell focusing in the fluorescence microscope before $\mathrm{APP}^{+}$exposure. The culturing media was supplemented with $1 \mu \mathrm{g} / \mathrm{ml}$ doxycycline 3 days before the experiments to induce the expression of DAT.

Intracellular $\mathbf{C a}^{2+}$ Determination. Cells were loaded with the $\mathrm{Ca}^{2+}$-sensitive dye Fura2, placed on the stage of the epifluorescence microscope (IX70; Olympus, Tokyo, Japan) equipped with a $20 \times 0.75$ numerical aperture objective, a fluorescence imaging attachment (Till Photonics, Graefelfing, Germany), and an electron multiplying charge-coupled device camera (Andor, Belfast, UK) (as described in Ruchala et al., 2014; Cameron et al., 2015). Measurements were performed with constant perfusion controlled by an automated and pressurized system (Automate Scientific, Berkeley, CA). The perfusing solutions were heated to $35^{\circ} \mathrm{C}$ using the ThermoClamp-1 System (Automate Scientific). Intermittent images were acquired alternating 340 and $380 \mathrm{~nm}$ excitation light, and ratio images were processed on-line at $3 \mathrm{~Hz}$. The experiments were performed using an imaging solution consisting of the following (in millimolar): $130 \mathrm{NaCl}, 4 \mathrm{KCl}$, $2 \mathrm{CaCl}_{2}, 1 \mathrm{MgCl}_{2}, 10 \mathrm{HEPES}$, and 10 glucose, at $\mathrm{pH}$ 7.3. As previously described, substrates of monoamine transporters (e.g., DA) generate $\mathrm{Ca}^{2+}$ signals in cells coexpressing these transporters and L-type voltage-gated channels, whereas monoamine transporter inhibitors (e.g., cocaine) fail to generate $\mathrm{Ca}^{2+}$ signals on their own but block substrate-induced signals (Ruchala et al., 2014; Cameron et al., 2015; Solis et al., 2017; Battisti et al., 2018). To test the effect of SRI-31142 in this system, cells were subjected to four phases of treatment over 110 seconds. First, a population of cells transfected with the $\mathrm{Ca}^{2+}$ channel was identified using enhanced green fluorescent protein fluorescence as a transfection marker, and the baseline of the Fura2 signal was recorded for 10 seconds. Second, cells were exposed to $10 \mu \mathrm{M}$ DA as a positive control for 5 seconds, followed by a wash for 30 seconds. Third, cells were then exposed to a single concentration of SRI-31142 for 30 seconds (to evaluate effects of SRI-31142 alone). Finally, the SRI-31142 exposure continued during the application of $5 \mu \mathrm{M}$ DA for 5 seconds (to evaluate the effectiveness of SRI-31142 to block DA effects), followed by a final wash for 30 seconds. Using this protocol, several concentrations of SRI-31142 were tested to generate a dose-response curve (each well was exposed only to a single 

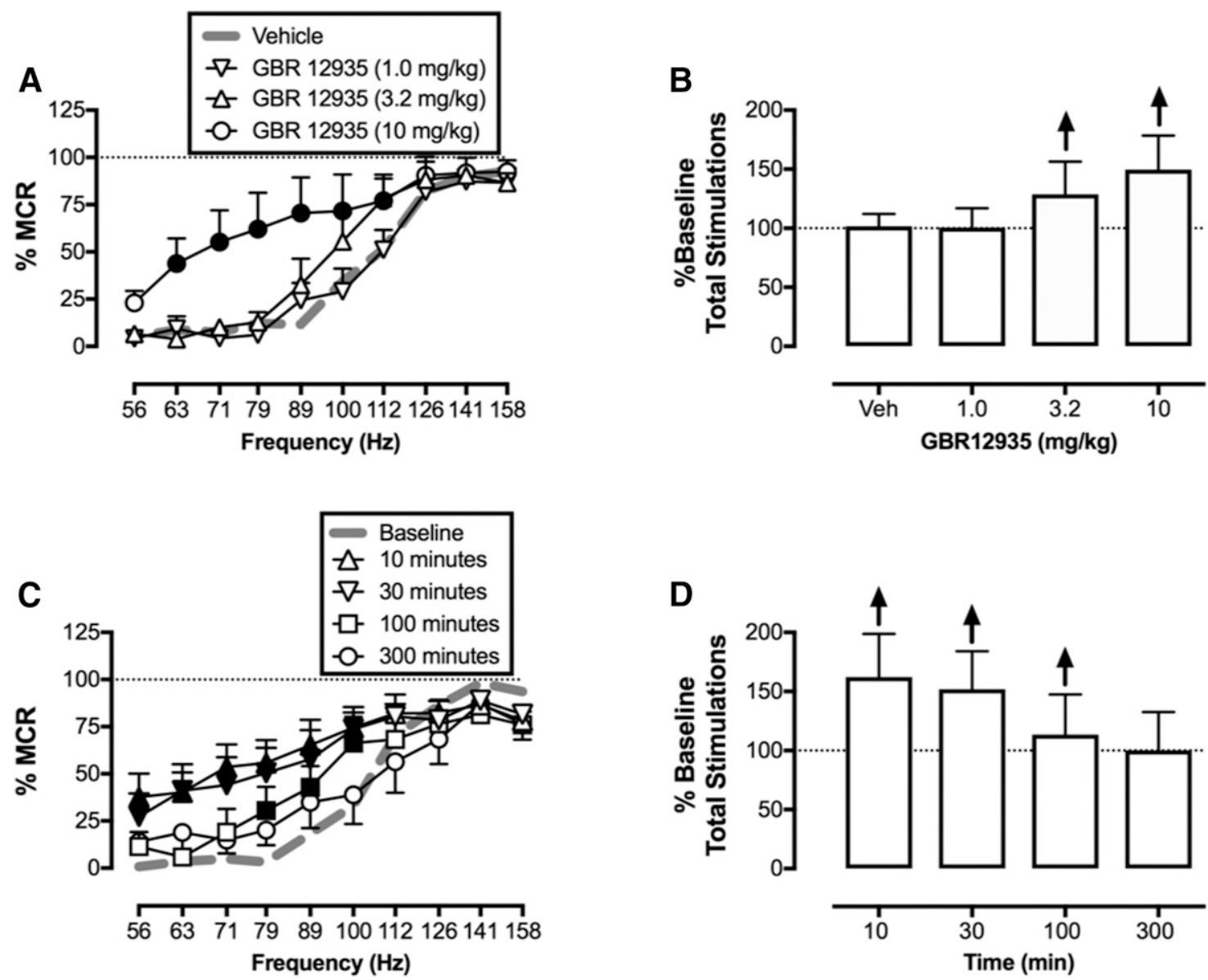

Fig. 2. Potency (A and B) and time course (C and D) of GBR-12935 effects on ICSS in rats $(n=6)$. All points and bars represent the mean \pm S.E.M. (A and C) Frequency-rate curves. Abscissae: electrical brain stimulation frequency in Hertz (log scale). Ordinates: ICSS reinforcement rate expressed as a percentage of MCR. Filled symbols indicate statistical significance $(P<0.05)$ compared with vehicle $(A)$ or baseline $(C)$. (B and D) Summary results for total stimulations earned across all frequencies expressed as a percentage of baseline for each frequency-rate curve in (A) and (C). Abscissae: Dose of GBR-12935 in milligrams per kilogram (B) or time after $10 \mathrm{mg} / \mathrm{kg}$ GBR-12935 in minutes (D). Ordinates: Percentage of the baseline number of total stimulations per component. Upward arrows indicate a significant increase in ICSS for at least one brain stimulation frequency, as shown in the corresponding left panel.

concentration of SRI-31142). An identical protocol was used to test the effects of cocaine administered alone or coapplied with $1 \mu \mathrm{M}$ SRI-31142.

The primary dependent variable was the amplitude of the $\mathrm{Ca}^{2+}$ signal during each phase of the study. For each cell, test data obtained during the application of test drug + DA (phase 4 above) were normalized to the control effect of DA alone (phase 2 above) using the following equation: normalized $\mathrm{Ca}^{2+}$ signal $=$ test signal/control signal. These data were then averaged across cells and plotted as a log dose-response curve using GraphPad Prism 5.0 software (GraphPad Software, La Jolla, CA), as described previously (Cameron et al., 2015; Solis et al., 2017). IC $_{50}$ values were compared by unpaired $t$ test, and the criterion for significance was $P<0.05$.

$\mathbf{A P P}^{+}$Uptake Studies. The assessment of drug effects on $\mathrm{Ca}^{2+}$ signals as described above relies on a multistep intracellular process whereby substrate passage through the transporter produces an inward depolarizing current that opens voltage-gated $\mathrm{Ca}^{2+}$ channels to permit $\mathrm{Ca}^{2+}$ entry and detection with a $\mathrm{Ca}^{2+}$ dye. This procedure can be used to evaluate drug effects as either transporter substrates or inhibitors. To provide a complementary and more direct assessment of drug effects as transporter inhibitors, drug effects were also examined on $\mathrm{APP}^{+}$-induced signals. $\mathrm{APP}^{+}$is a DAT substrate that fluoresces when it is taken up by cells and interacts with intracellular components (Solis et al., 2012). Using fluorescence microscopy, the activity of DAT can be monitored in living cells exposed to $\mathrm{APP}^{+}$.
The DsRed signal of transfected cells was used to find the focal plane of the cell monolayer, and the $\mathrm{APP}^{+}$signal was then measured using an excitation wavelength of $460 \mathrm{~nm}$ (Ruchala et al., 2014). Experiments were performed in three phases over 100 seconds under constant perfusion at room temperature with an acquisition rate of $10 \mathrm{~Hz}$. Specifically, cells were exposed to 1) imaging solution for 10 seconds, 2) cocaine $\pm 1 \mu \mathrm{M}$ SRI-31142 for 30 seconds, and 3) cocaine $\pm 1 \mu \mathrm{M}$ SRI-31142 $+\mathrm{APP}^{+}$for 60 seconds. Different cocaine concentrations with and without SRI-31142 were evaluated in different cells.

The first derivative of the $\mathrm{APP}^{+}$signal was calculated as a function of time to obtain the rate of $\mathrm{APP}^{+}$uptake in arbitrary fluorescence units per second using GraphPad Prism 5.0 software. The rate traces of 60 cells/well were averaged, and cocaine effects on the peak of the curve for each well (maximal uptake rate) were used to generate a log dose-response curve using GraphPad Prism 5.0 software. IC $_{50}$ values for cocaine applied alone or in combination with SRI-31142 were compared by unpaired $t$ test, and the criterion for significance was $P<0.05$. Each data point corresponds to five to seven wells on 3 different days of experiments.

\section{Drugs}

GBR-12935 was purchased from Sigma-Aldrich and dissolved in saline. SRI-31142 was provided by S.A. (Southern Research) and 

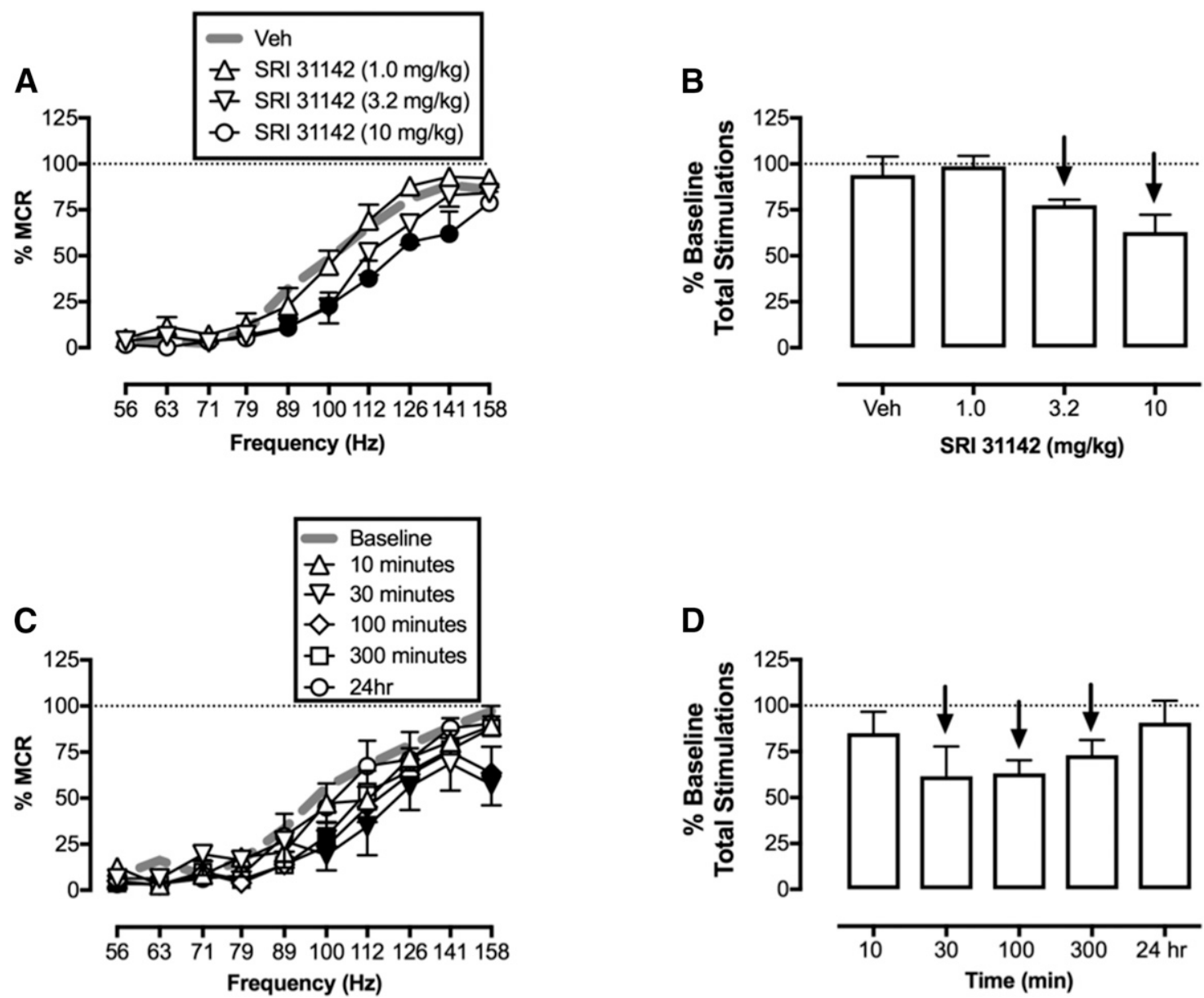

Fig. 3. Potency (A and B) $(n=5)$ and time course $(\mathrm{C}$ and D) $(n=6)$ of SRI-31142 effects on ICSS in rats. All points and bars represent the mean \pm S.E.M. (A and C) Frequency-rate curves. Abscissae: Electrical brain stimulation frequency in Hertz (log scale). Ordinates: ICSS rate expressed as a percentage of MCR. Filled symbols indicate statistical significance $(P<0.05)$ compared with vehicle $(A)$ or baseline $(C)$. (B and D) Summary results for total stimulations earned across all frequencies expressed as a percentage of baseline for each frequency-rate curve in (A) and (C). Abscissae: Dose SRI-31142 in milligram per kilogram (B) or time after $10 \mathrm{mg} / \mathrm{kg}$ SRI-31142 administration in minutes (D). Ordinates: Percentage of the baseline number of total stimulations per component. Downward arrows indicate a significant decrease in ICSS for at least one brain stimulation frequency, as shown in the corresponding left panel.

dissolved in $\mathrm{DMSO} /$ saline at a 6:4 ratio. Cocaine $\mathrm{HCl}$ was provided by the National Institute on Drug Abuse Drug Supply Program (Bethesda, MD) and was dissolved in either DMSO/saline (6:4 ratio) or saline, as described above. All drugs were injected intraperitoneally in a volume of $1 \mathrm{ml} / \mathrm{kg}$.

\section{Results}

ICSS. Under baseline conditions, electrical brain stimulation maintained a frequency-dependent increase in ICSS rates of responding. For the 21 rats used in these studies, the mean \pm S.E.M. baseline maximum control rate was $63.99 \pm 2.245$ stimulations/trial, and the mean \pm S.E.M. number of total baseline stimulations was $260.69 \pm 19.49$ stimulations/component.

Figure 2 shows that GBR-12935 produced dose- and timedependent increases in ICSS responding. Specifically, in doseeffect studies, the lowest dose of $1.0 \mathrm{mg} / \mathrm{kg}$ did not significantly alter ICSS, whereas a dose of $3.2 \mathrm{mg} / \mathrm{kg}$ increased ICSS at one frequency $(112 \mathrm{~Hz})$, and $10 \mathrm{mg} / \mathrm{kg}$ facilitated ICSS across a broad range of six frequencies $(63-112 \mathrm{~Hz})$ (frequency: $F_{(9,45)}=$ 101.7, $P<0.001$; dose: $F_{(3,15)}=3.107$, N.S.; frequency $\times$ dose: $\left.F_{(27,135)}=2.369, P=0.0006\right)$. In the time-course study,
$10 \mathrm{mg} / \mathrm{kg}$ GBR-12935 produced maximal facilitation of ICSS at the earliest time points (10 and 30 minutes), and significant ICSS facilitation was no longer apparent after 300 minutes (frequency: $F_{(9,45)}=27.18, P<0.0001$; time: $F_{(4,20)}=8.855$, $P=0.0003$; frequency $\times$ time: $\left.F_{(36,180)}=3.187, P<0.0001\right)$.

Figure 3 shows that, in contrast to GBR-12935, SRI-31142 produced dose- and time-dependent depression of ICSS. The low dose of $1.0 \mathrm{mg} / \mathrm{kg}$ SRI-31142 did not significantly alter ICSS. A higher dose of $3.2 \mathrm{mg} / \mathrm{kg}$ SRI-31142 depressed ICSS at two frequencies ( 89 and $100 \mathrm{~Hz}$ ), and a dose of $10.0 \mathrm{mg} / \mathrm{kg} \mathrm{SRI-}$ 31142 depressed ICSS across a broad range of five frequencies $(89-141 \mathrm{~Hz})$ (frequency: $F_{(9,36)}=69.68, P<0.0001$; dose: $F_{(3,12)}=5.526, P=0.0128$; frequency $\times$ dose: $F_{(27,108)}=1.887$, $P=0.0117)$. In the time-course study, $10 \mathrm{mg} / \mathrm{kg}$ SRI-31142 produced maximal depression of ICSS after 30 minutes, and significant ICSS depression was no longer apparent after 24 hours (frequency: $F_{(9,45)}=56.80, P<0.0001$; time: $F_{(5,25)}=$ 1.961 , ns; frequency $\times$ time: $\left.F_{(45,225)}=1.568, P=0.0182\right)$. The effects of $10 \mathrm{mg} / \mathrm{kg}$ cocaine dissolved in the DMSO/saline (6:4 ratio) vehicle were also compared with vehicle effects in rats from this group as a positive control. Like $10 \mathrm{mg} / \mathrm{kg}$ GBR-12935, $10 \mathrm{mg} / \mathrm{kg}$ cocaine significantly increased ICSS 

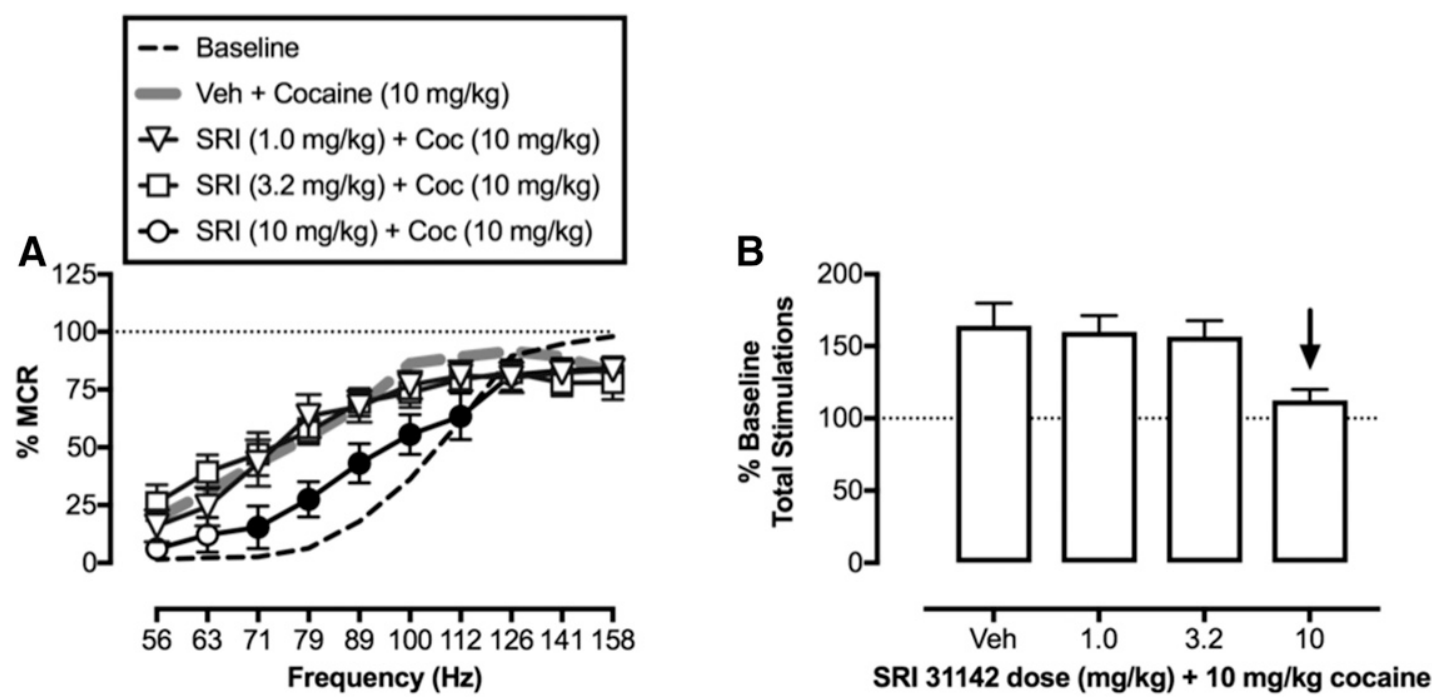

Fig. 4. Effects of $10 \mathrm{mg} / \mathrm{kg}$ cocaine administered after pretreatment with SRI-31142 on ICSS in rats $(n=6)$. All points and bars represent the mean \pm S.E.M. (A) Frequency-rate curves. Abscissa: Electrical brain stimulation frequency in Hertz (log scale). Ordinate: ICSS rate expressed as a percentage of MCR. Filled symbols indicate statistical significance $(P<0.05)$ compared with vehicle $+10 \mathrm{mg} / \mathrm{kg}$ cocaine. (B) Summary results for total stimulations earned across all frequencies expressed as a percentage of baseline for each frequency-rate curve in (A). Downward arrow indicates a significant decrease in ICSS relative to vehicle $+10 \mathrm{mg} / \mathrm{kg}$ cocaine for at least one brain stimulation frequency as shown in the left panel.

across a broad range of frequencies $(56-100 \mathrm{~Hz}$; frequency: $F_{(9,54)}=25.18, P<0.0001$; dose: $F_{(1,6)}=9.354, P=0.0223$; frequency $\times$ dose: $F_{(9,54)}=13.0000, P<0.0001$; data not shown).

Figure 4 shows the effects of SRI-31142 as a pretreatment to $10 \mathrm{mg} / \mathrm{kg}$ cocaine in ICSS. After pretreatment with the SRI31142 vehicle, $10 \mathrm{mg} / \mathrm{kg}$ cocaine facilitated ICSS responding. Low doses of 1.0 and $3.2 \mathrm{mg} / \mathrm{kg}$ SRI-31142 did not alter this effect of cocaine; however, $10 \mathrm{mg} / \mathrm{kg}$ SRI-31142 significantly attenuated the facilitation of ICSS responding produced by $10 \mathrm{mg} / \mathrm{kg}$ cocaine (SRI-31142 dose: $F_{(3,18)}=5.164, P=0.0095$; frequency $\times$ SRI-31142 dose: $\left.F_{(27,162)}=1.75, P=0.0181\right)$.

Microdialysis. The mean \pm S.E.M. baseline DA and 5-HT levels for all rats in the study were $1.35 \pm 0.19 \mathrm{pg} / 9 \mu \mathrm{l}(0.98 \pm$ $0.14 \mathrm{nM})$ and $0.23 \pm 0.02 \mathrm{pg} / 9 \mu \mathrm{l}(0.15 \pm 0.01 \mathrm{nM})$, respectively. There were no between-group differences in baseline DA $\left(F_{(3,16)}=0.70, \mathrm{~ns}\right)$ or 5 -HT $\left(F_{(3,16)}=0.78, \mathrm{~ns}\right)$, and all cannula placements were in the NAc core and/or shell (Fig. 5).

Figure 6 shows the effect of vehicle or $10 \mathrm{mg} / \mathrm{kg}$ SRI-31142 administered alone on baseline DA (Fig. 6A) and 5-HT (Fig. 6B) levels. Relative to vehicle, SRI-31142 decreased baseline DA levels from 90 to 120 minutes after injection (time: $F_{(12,96)}=7.668, P<0.0001$; treatment: $F_{(1,8)}=3.432$, N.S.; time $\times$ treatment: $\left.F_{(12,96)}=12.50, P<0.0001\right)$ and increased baseline 5-HT levels 40 minutes after injection (time: $F_{(7,56)}=$ 3.035, $P=0.0089$; treatment: $F_{(1,8)}=3.051$, N.S.; time $\times$ treatment: $F_{(7,56)}=3.17, P=0.0068$ ). (Note that one rat treated with $10 \mathrm{mg} / \mathrm{kg}$ SRI-31142 was missing 5 -HT data from 80 to 120 minutes because of technical difficulties, so data were analyzed only through 70 minutes; data in the graph from 80 to 120 minutes show results for $n=4$ and were excluded from the analysis.) Figure 6 also shows the effects of $10 \mathrm{mg} / \mathrm{kg}$ cocaine administered after a pretreatment with vehicle or $10 \mathrm{mg} / \mathrm{kg}$ SRI-31142 on DA (Fig. 6C) or 5-HT (Fig. $6 \mathrm{D})$. After vehicle pretreatment, cocaine increased the mean levels of DA and 5-HT. SRI-31142 pretreatment resulted in lower DA levels from 60 to 80 minutes after cocaine injection (time: $F_{(12,96)}=4.85, P<0.0001$; treatment: $F_{(1,8)}=5.565, P=$ 0.046 ; time $\times$ treatment: $\left.F_{(12,96)}=4.55, P<0.0001\right)$. In contrast, SRI-31142 did not alter the 5-HT-increasing effects of cocaine (time: $F_{(12,96)}=19.3, P<0.0001$; treatment: $F_{(1,8)}=$ $0.1862, \mathrm{~ns}$; time $\times$ treatment: $F_{(12,96)}=2.33, P=0.01$ ).

Pharmacokinetic Studies. Table 1 shows the results of pharmacokinetic studies. Maximum concentrations were observed after 10 minutes in both plasma and brain, and plasma levels exceeded brain levels by 32.4-fold. However, the maximum brain concentration $(77.1 \mathrm{nM})$ exceeded the reported potency of SRI-31142 to inhibit DA uptake in rat brain synaptosomes $\left(\mathrm{IC}_{50}\right.$ $=1.9 \mathrm{nM})($ Rothman et al., 2015) by 40.6 -fold.

Receptor Binding Screen. Table 2 shows the results of receptor binding studies. Of the 45 targets investigated, SRI31142 had the highest affinity for mu opioid receptors [inhibitor constant $\left(K_{\mathrm{i}}\right)=116 \mathrm{nM}$ ], and SRI-31142 affinity for the human DAT $\left(K_{\mathrm{i}}=3520 \mathrm{nM}\right)$ was similar to its previously published affinity for the rat DAT $\left(\mathrm{IC}_{50}=2340 \mathrm{nM}\right.$ ) (Rothman et al., 2015). However, the maximum brain concentration of SRI31142 observed in pharmacokinetic studies was lower than the SRI-31142 $K_{\mathrm{i}}$ value for any of the 45 targets examined.

DAT Activity Measured Using Live Cell Imaging. Figure 7 shows the effects of SRI-31142 and cocaine on DATmediated signals in living cells. When SRI-31142 was administered alone at concentrations up to $10 \mu \mathrm{M}$ in an assay of $\mathrm{Ca}^{2+}$ signaling, it failed to produce either a substrate-like increase in the $\mathrm{Ca}^{2+}$ signal or an inhibitor-like blockade of the $\mathrm{Ca}^{2+}$ signal elicited by the DAT substrate DA (Fig. 6, A and B). Consistent with its function as a DAT inhibitor, cocaine also failed to produce a substrate-like increase in the $\mathrm{Ca}^{2+}$ signal, but, in contrast to SRI-31142, cocaine did produce a concentration-dependent decrease in the DA-elicited $\mathrm{Ca}^{2+}$ signal (Fig. 6, C and D). Coadministration of $1 \mu \mathrm{M}$ SRI-31142 + cocaine produced a significant but small 1.5 -fold decrease in the potency of cocaine to inhibit the DA-elicited $\mathrm{Ca}^{2+}$ signal (Fig. $6 \mathrm{D})\left(\mathrm{IC}_{50} \pm\right.$ S.E.M.: for cocaine alone, $626 \pm 60 \mathrm{nM}$; for cocaine + $1 \mu \mathrm{M}$ SRI-31142, $918 \pm 74 \mathrm{nM} ; P=0.0046)$. In the complementary assay of $\mathrm{APP}^{+}$signaling, cocaine again produced a concentration-dependent decrease in the $\mathrm{APP}^{+}$signal, but in this assay, the coadministration of $1 \mu \mathrm{M}$ SRI-31142 failed to 

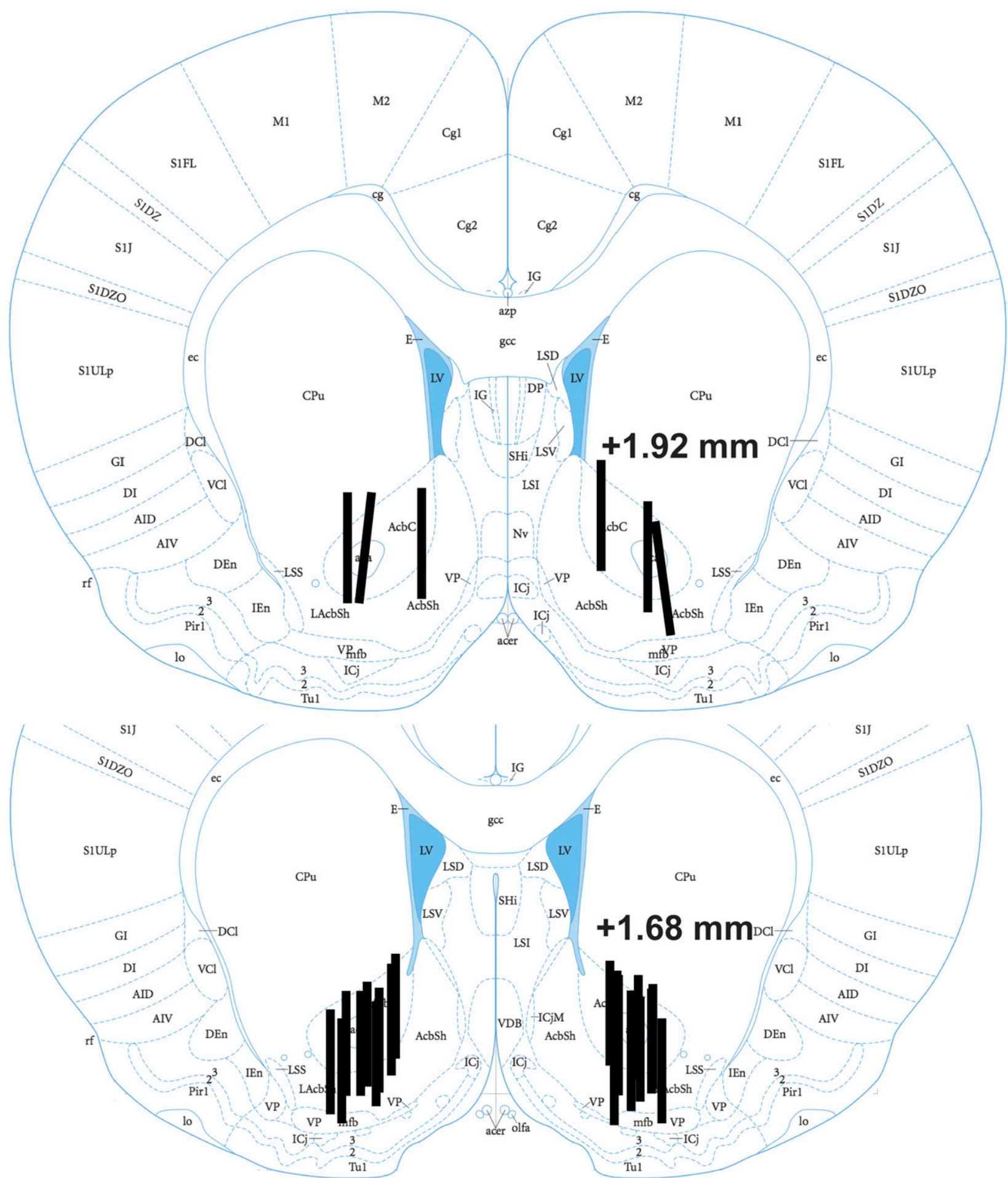

Fig. 5. Coronal sections showing probe placements in rats used in microdialysis studies. Numbers indicate the anterior position of the slice relative to bregma. Figures were produced based on comparisons to the findings of Paxinos and Watson (2007).

alter the potency of cocaine (Fig. $6, \mathrm{E}$ and $\mathrm{F})\left(\mathrm{IC}_{50} \pm\right.$ S.E.M.: for cocaine alone, $190 \pm 48 \mathrm{nM}$; for cocaine $+1 \mu \mathrm{M}$ SRI-31142, $195 \pm 40 \mathrm{nM} ; P=0.93)$.

\section{Discussion}

This study compared neurochemical and behavioral effects of the putative allosteric DAT inhibitor SRI-31142 with effects of the DA uptake inhibitors GBR-12935 and cocaine in rats. In rat brain synaptosomes, SRI-31142 had high nanomolar potency to inhibit monoamine uptake but much weaker potency to inhibit DAT binding or DAT-mediated monoamine efflux. This profile of activity was interpreted as evidence of DAT inhibition via an allosteric site distinct from the DA binding site (Rothman et al., 2015). We hypothesized that SRI31142 would increase ICSS and NAc DA and 5-HT levels, and 
A

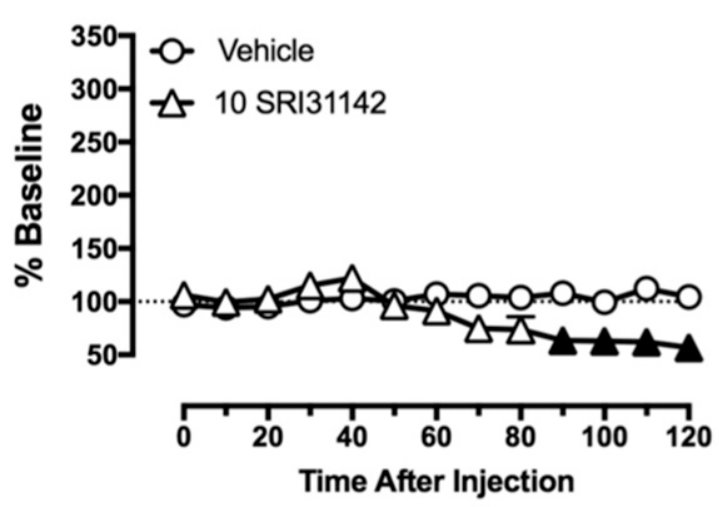

C

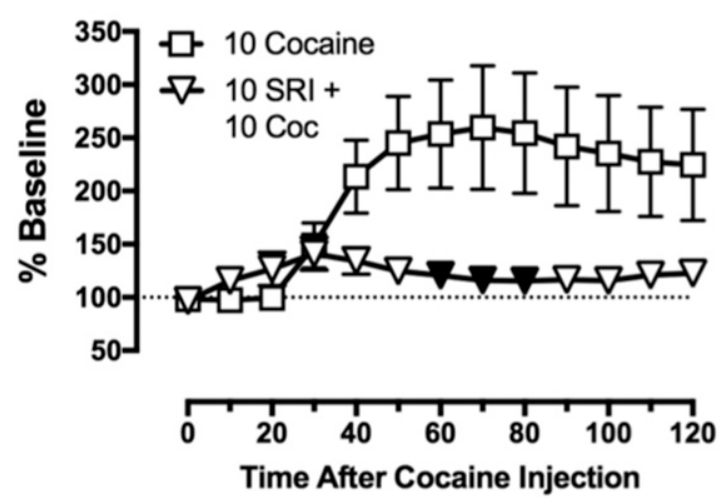

B
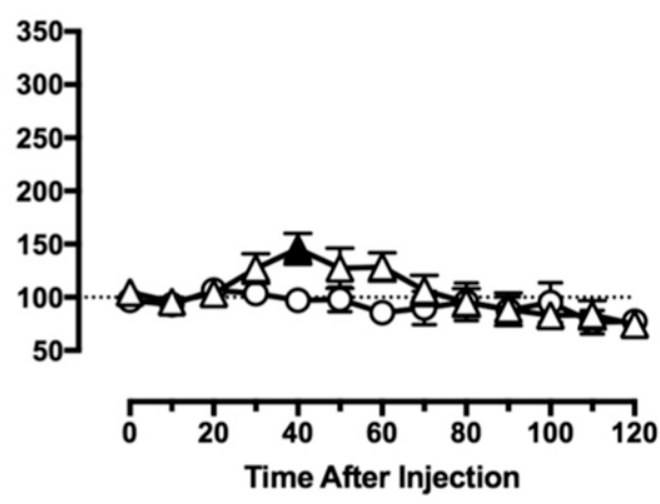

Serotonin

D

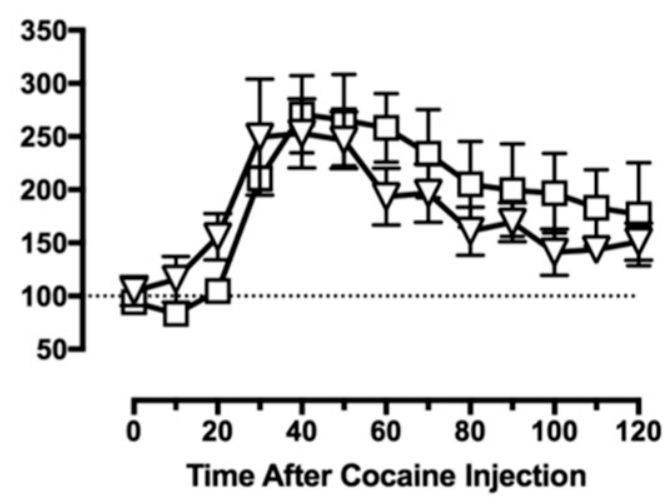

Fig. 6. Effects of $10 \mathrm{mg} / \mathrm{kg}$ SRI-31142 alone (A and B) or as a pretreatment to $10 \mathrm{mg} / \mathrm{kg}$ cocaine (C and D) on DA and 5-HT levels measured using microdialysis in rats $(n=5$ for each condition). All points and bars represent the mean \pm S.E.M. Abscissae: Time in minutes after drug administration. Ordinates: Levels of DA (A and C) or 5-HT (B and D) expressed as a percentage of baseline level. Filled symbols indicate statistical significance $(P<0.05)$ compared with vehicle (A and B) or $10 \mathrm{mg} / \mathrm{kg}$ cocaine (C and D).

that it would not block cocaine-induced increases in ICSS or NAc DA or 5-HT levels. There were two major findings, neither of which supported our working hypotheses. First, unlike GBR-12935 and cocaine, SRI-31142 failed to produce an abuse-related increase in ICSS or NAc DA levels, and instead produced only a dose- and time-dependent depression of these endpoints. Second, SRI-31142 blocked cocaineinduced increases in ICSS and NAc DA levels, although only at an SRI-31142 dose that decreased ICSS and NAc DA levels in the absence of cocaine. These results suggest that SRI31142 does not have psychostimulant-like abuse potential. The blockade of cocaine effects raises the possibility that SRI31142 might warrant further consideration as a candidate treatment of cocaine abuse; however, the utility of SRI-31142 as a pharmacotherapy agent would likely be limited by side effects (e.g., motor impairment). Additional studies investigating the possible mechanisms of SRI-31142 effects suggested poor brain penetration, a lack of plausible non-DAT targets, and a failure to observe evidence for either DAT inhibition or reliable cocaine antagonism by SRI-31142 in assays of DAT function. Overall, our results suggest that SRI31142 does not produce abuse-related behavioral or neurochemical effects and that it attenuates cocaine effects by acting via a non-DAT mechanism of action.

We were interested in evaluating the effects of putative allosteric DAT modulators because of their potential to produce effects that might differ from typical DAT inhibitors. We focused on SRI-31142 because it is representative of other compounds in this series in having high nanomolar potency to inhibit monoamine uptake via DAT, similar to that of GBR-12935; however, relative to GBR-12935, SRI-31142 has only partial efficacy to inhibit DAT-mediated uptake and much weaker potency and/or efficacy to inhibit DAT-mediated monoamine efflux and radioligand binding to DAT (Rothman et al., 2015).

Abuse-related effects are one limitation of typical DAT inhibitors that restricts their clinical utility; thus, a primary goal of the current study was to assess the abuse potential of SRI-31142 in comparison with the typical DAT inhibitors cocaine and GBR-12935. Consistent with previous studies using these and other typical DAT inhibitors, both GBR-12935 and cocaine produced ICSS facilitation (Rosenberg et al., 2013; Bonano et al., 2014b; Lazenka and Negus, 2017), and cocaine also increased NAc DA levels (Di Chiara and Imperato, 1988;

TABLE 1

Pharmacokinetic parameters for plasma and brain distribution of SRI31142 after administration of $10 \mathrm{mg} / \mathrm{kg}$, i.p.

\begin{tabular}{lcc}
\hline Parameter & Brain & Plasma \\
\hline $\mathrm{T}_{\max }$ & $10 \mathrm{~min}$ & $10 \mathrm{~min}$ \\
$C_{\max }$ & $35.2 \mathrm{ng} / \mathrm{ml}(77.1 \mathrm{nM})$ & $1125 \mathrm{ng} / \mathrm{ml}(2.5 \mu \mathrm{M})$ \\
$t_{1 / 2}$ & Not determined & $4.4 \mathrm{~h}$ \\
$\mathrm{AUC}$ & $18.2 \mathrm{~h} / \mathrm{ng}$ per milliliter & $880 \mathrm{~h} / \mathrm{ng}$ per milliliter
\end{tabular}

AUC, area under the curve; $t_{1 / 2}$, half-life. 
TABLE 2

$K_{\mathrm{i}}$ values (nanomolar) for SRI-31142 at different receptor targets as determined by the PDSP

Previously published data on the potency of the compound to inhibit DAT-mediated monoamine uptake and bind to DAT are also shown for comparison.

\begin{tabular}{lc}
\hline \multicolumn{1}{c}{ Receptor Target } & $K_{\mathrm{i}}$ Value \\
\cline { 2 - 2 } & $\mathrm{nM}$ \\
\hline DAT uptake inhibition $\left(\mathrm{IC}_{50}\right)$ & $1.9^{a}$ \\
Rat DAT $\left(\mathrm{IC}_{50}\right)$ & $2340^{a}$ \\
Mu opioid & $116^{b}$ \\
Peripheral BZP & $491^{b}$ \\
Histamine H2 & $617^{b}$ \\
Norepinephrine alpha 2B & $1177^{b}$ \\
5-HT 5-HT7 & $1218^{b}$ \\
Acetylcholine M4 & $1261^{b}$ \\
Delta opioid & $1390^{b}$ \\
DA D3 & $1528^{b}$ \\
Acetylcholine M2 & $1612^{b}$ \\
BZP site & $1633^{b}$ \\
Kappa opioid & $2413^{b}$ \\
Acetylcholine M1 & $2470^{b}$ \\
Norepinephrine beta 3 & $2654^{b}$ \\
Norepinephrine alpha 2A & $2737^{b}$ \\
Human DAT & $3520^{b}$ \\
Acetylcholine M5 & $5229^{b}$ \\
Histamine H4 & $5535^{b}$ \\
Histamine H1 & $5585^{b}$ \\
Acetylcholine M3 & $5951^{b}$ \\
Other ${ }^{c}$ & $>10,000^{b}$ \\
\hline
\end{tabular}

BZP, benzodiazepine.

${ }^{a}$ From Rothman et al. (2015) using $\left[{ }^{3} \mathrm{H}\right] \mathrm{WIN} 354428$ as the radioligand. The same radioligand is used for DAT in PDSP.

${ }^{b}$ From PDSP.

${ }^{c}$ Other sites with $K_{\mathrm{i}}$ values $>10,000 \mathrm{nM}$ were $5-\mathrm{HT} 1 \mathrm{~A} / \mathrm{B} / \mathrm{D} / \mathrm{E}, 5-\mathrm{HT} 2 \mathrm{~A} / \mathrm{B} / \mathrm{C}, 5-\mathrm{HT} 3$, 5-HT5a, 5-HT6, norepinephrine alpha $1 \mathrm{~A} / 1 \mathrm{~B} / 1 \mathrm{D}$, norepinephrine alpha $2 \mathrm{C}$, norepinephrine beta 1/2, DA D1/2/4/5, GABA, H3, NET, SERT, and Sigma 1/2.

Schindler et al., 2016; Johnson et al., 2018). In contrast, SRI-31142 had no effect on ICSS up to a dose of $10 \mathrm{mg} / \mathrm{kg}$, which depressed behavior. Similarly, SRI-31142 administered alone only decreased NAc DA levels. Thus, unlike both GBR-12935 and cocaine, SRI-31142 failed to produce abuserelated effects in either of these procedures.

SRI-31142 can be categorized as an atypical DAT inhibitor by virtue of both its in vitro and in vivo pharmacological profiles. Other types of atypical DAT inhibitors have also been identified that preferentially bind intracellular-facing rather than extracellular-facing DAT conformations, that bind other targets in addition to DAT, and that may also fail to produce typical psychostimulant-like patterns of in vivo behavioral or neurochemical effects (Reith et al., 2015). However, although other atypical DAT inhibitors may fail to produce psychostimulant-like behavioral effects, they generally do produce at least some increase in NAc DA levels as assessed by microdialysis. Thus, SRI-31142 differs from other types of atypical DAT inhibitors not only in its much higher potency to inhibit DAT-mediated monoamine influx than monoamine efflux or DAT binding in rat brain synaptosomes (Rothman et al., 2015), but also by its failure to produce any evidence for increased NAc DA at behaviorally active doses in rats.

In the present study, SRI-31142 dose-dependently blocked cocaine-induced increases in both ICSS and NAc DA levels, but not in NAc 5-HT levels. This suggests that SRI-31142 may warrant further study as a candidate treatment of cocaine abuse for three reasons. First, after SRI-31142 pretreatment, cocaine increased NAc 5-HT levels without increasing NAc DA levels, and drugs (e.g., citalopram, fenfluramine) that increase
NAc 5-HT without increasing NAc DA levels typically have low abuse liability (Bauer et al., 2013; Rosenberg et al., 2013; Suyama et al., 2016). Second, the modulation of cocaine effects by SRI-31142 resembles the modulation of cocaine effects by amphetamine maintenance, which is effective to reduce cocaine self-administration in rats, nonhuman primates, and humans, and to reduce cocaine use in clinical trials (Negus and Henningfield, 2015; Johnson et al., 2018). Last, both typical DAT inhibitors (Glowa et al., 1995; Lindsey et al., 2004; Rothman et al., 2008; Negus et al., 2009) and atypical DAT inhibitors (Reith et al., 2015; Zanettini et al., 2018) have also been found to decrease cocaine self-administration in laboratory animals and, in at least some cases, to also attenuate cocaine-induced increases in NAc DA release (Baumann et al., 1994; Tanda et al., 2009). However, the $10 \mathrm{mg} / \mathrm{kg}$ dose of SRI31142 that produced these anticocaine effects also decreased ICSS and NAc DA levels when administered alone, and this profile of results suggests two concerns. First, it raises the possibility that SRI-31142 did not block cocaine effects at the DAT, but rather produced opposing effects via some other intracellular or intercellular mechanism that combined with and nullified cocaine effects. Additional evidence is provided below to support this possibility. Second, it suggests that SRI31142 might produce unacceptable side effects at doses necessary to block cocaine effects. For example, kappa opioid receptor agonists have also been found to block cocaine effects on ICSS and NAc DA levels only at doses that also decrease ICSS and NAc DA levels when administered alone (Maisonneuve et al., 1994; Bonano et al., 2014b); however, in humans, kappa agonists failed to reduce cocaine use at doses up to those that produced side effects (Walsh et al., 2001).

Further studies were initiated to determine a possible mechanism by which SRI-31142 might produce its unexpected profile of effects. One possibility was that SRI-31142 was not penetrating the blood-brain barrier at sufficient concentrations to inhibit NAc DA uptake in vivo as it did in rat brain synaptosomes in vitro (Rothman et al., 2015). In pharmacokinetic studies, systemic administration of a behaviorally active SRI-31142 dose $(10 \mathrm{mg} / \mathrm{kg})$ produced relatively low brain-to-plasma drug concentrations, suggestive of poor brain distribution. Moreover, some of the apparent brain concentration may have reflected residual drug in cerebrovasculature rather than in brain tissue. Nonetheless, the peak brain SRI-31142 concentration (77.1 nM) was more than 30-fold higher than the $\mathrm{IC}_{50}$ value to inhibit DA uptake in synaptosomes (1.9 nM) (Rothman et al., 2015), and SRI-31142induced decreases in both basal and cocaine-enhanced NAc DA levels also suggest brain distribution. A second possibility was that SRI-31142 brain concentrations were sufficient to produce effects at other receptor targets that might mask or oppose DATmediated effects. However, peak SRI-31142 brain concentrations were below the $K_{\mathrm{i}}$ value for all of the 45 different receptors examined in a receptor-binding screen, and none of the higheraffinity targets are obvious candidates to mediate the observed constellation of SRI-31142 effects. For example, SRI-31142 displayed the highest affinity for the mu opioid receptor $\left(K_{\mathrm{i}}=\right.$ $116 \mathrm{nM}$ ), but the profile of SRI-31142 effects is not consistent with either mu agonist or antagonist effects. Mu agonists increase rather than decrease NAc DA (Di Chiara and Imperato, 1988), and mu antagonists do not depress ICSS (Sakloth and Negus 2018). SRI-31142 also displayed affinity for the kappa opioid receptor similar to its affinity for DAT, and as noted above, both SRI-31142 and kappa agonists 

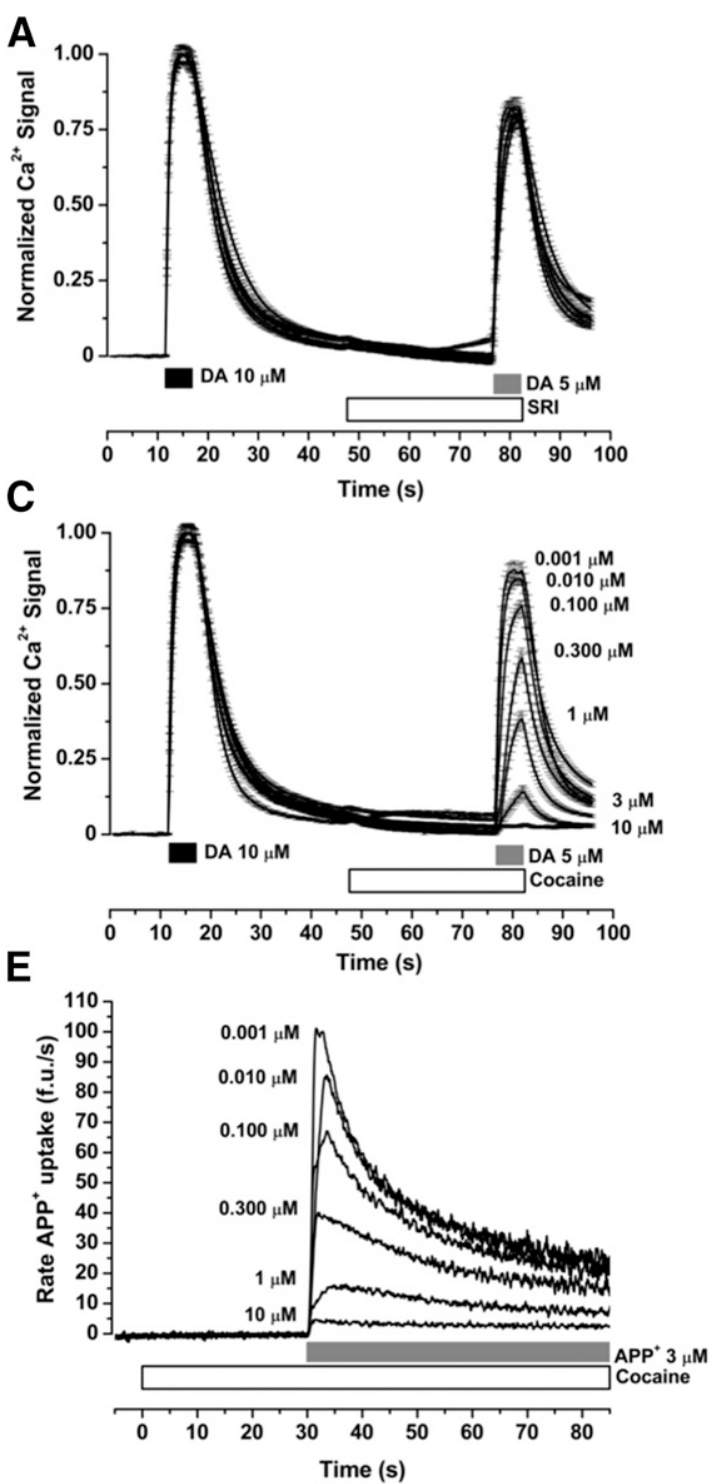
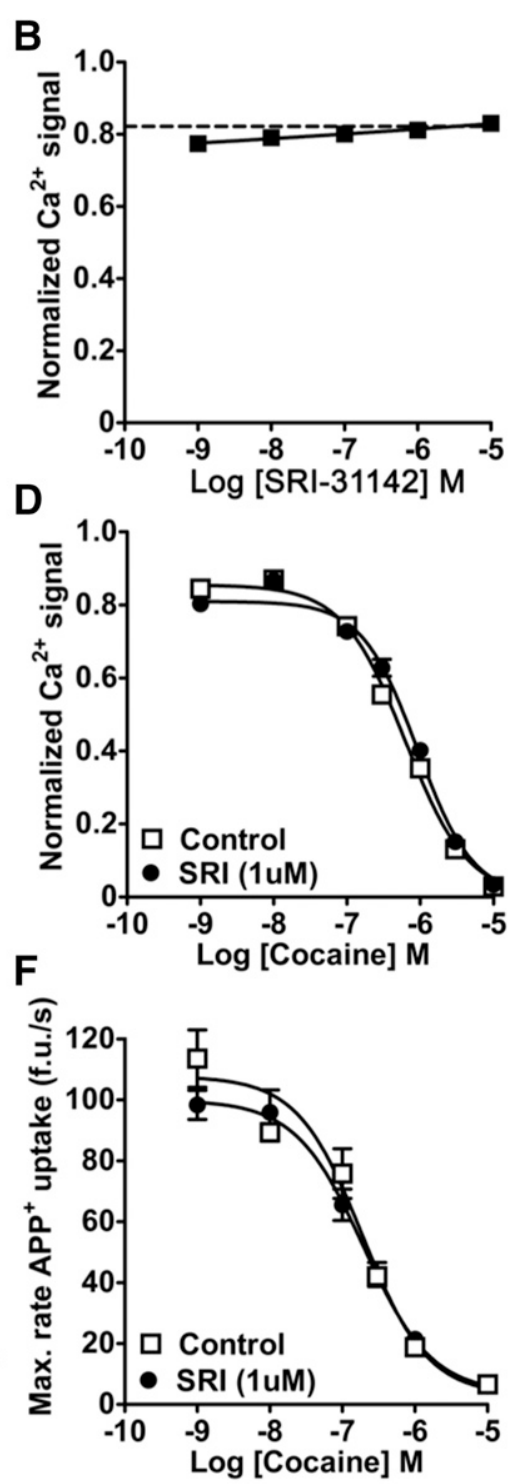

Fig. 7. Effects of SRI-31142 and cocaine administered alone or in combination on DAT-mediated signaling in living cells. The effects of SRI-31142 (A and B) or cocaine with and without SRI-31142 (C and D) on $\mathrm{Ca}^{2+}$ signals in cells expressing both DAT and voltage-gated $\mathrm{Ca}^{2+}$ channels and loaded with the $\mathrm{Ca}^{2+}$ dye Fura2. In these cells, DAT substrates like DA induce a depolarizing current, open $\mathrm{Ca}^{2+}$ channels, and increase the signal of the $\mathrm{Ca}^{2+}$ dye. (A and C) The time course of $\mathrm{Ca}^{2+}$ signals. Abscissae: Time in seconds. The times of treatment applications are indicated above the abscissa. (B and D) The concentration-effect curves for treatments to block the DA-induced $\mathrm{Ca}^{2+}$ signal. Abscissa: Log concentration of SRI-31142 (B) or cocaine with and without $1 \mu \mathrm{M}$ SRI-31142 (D). Ordinates: Normalized $\mathrm{Ca}^{2+}$ signal expressed as a fraction of the peak signal produced by $10 \mu \mathrm{M}$ DA. All data show the mean \pm S.E.M. of $\geq 31$ cells/treatment. (E and F) The effects of cocaine with and without SRI-31142 on $\mathrm{APP}^{+}$signals in cells expressing DAT. In these cells, $\mathrm{APP}^{+}$is a DAT substrate that fluoresces upon entry into the cell. (E) The time course of mean $\mathrm{APP}^{+}$ signals after the administration of various cocaine concentrations. Abscissae: Time in seconds. The times of treatment applications are indicated above the abscissa. Ordinate: The rate of $\mathrm{APP}^{+}$uptake in arbitrary fluorescence units per second. (F) The concentration-effect curves for cocaine with and without SRI-31142 to inhibit the $\mathrm{APP}^{+}$signal. Abscissa: Log concentration of cocaine with and without $1 \mu \mathrm{M}$ SRI-31142. Ordinates: Maximum rate of $\mathrm{APP}^{+}$uptake. All data show the mean \pm S.E.M. of five or more wells of cells per concentration.

decrease baseline and cocaine-enhanced ICSS and NAc DA; however, in contrast to SRI-31142, kappa agonists increase rather than decrease DAT-mediated transport (Kivell et al., 2014). It remains possible that SRI-31142 acted on some other receptor targets or on a peripheral receptor target, but the identity of any important non-DAT target remains to be determined.

A final possibility was that partial DAT inhibition by SRI31142 , as measured in rat brain synaptosomes, may depend on a relatively restricted range of experimental conditions. For example, initial studies found that these compounds differ from typical DAT inhibitors in having higher potency and/or efficacy to block DAT-mediated monoamine influx than efflux, so one determinant of DAT inhibition by these compounds is the direction of monoamine transport across the membrane (Rothman et al., 2015). In the present study, SRI-31142 effects on DAT function were further evaluated using imaging procedures to assess DAT-mediated fluorescent signals in live cells. Previous studies have shown a high correlation between drug effects in rat brain synaptosomes and in this assay of DAT-mediated fluorescent signals (Solis et al., 2017; Battisti et al., 2018); however, SRI-31142 effects were not consistent across assays. Specifically, in contrast to findings in rat brain synaptosomes, SRI-31142 failed to produce a cocaine-like blockade of DAT-mediated fluorescent signals. The reason for this discrepancy remains to be determined, but these results provide further evidence for the narrow range of experimental conditions under which these compounds produce evidence for DAT inhibition. Cellular imaging studies were also used to compare in vivo and in vitro effectiveness of SRI-31142 to block cocaine effects. In contrast to the effectiveness of SRI-31142 in blocking cocaine-induced increases in both ICSS and NAc DA levels in vivo, SRI-31142 produced only weak and unreliable antagonism of cocaine effects in vitro. These results suggest that SRI-31142 blockade of cocaine effects on ICSS and NAc DA may not be via DAT. Rather, as discussed above, these results suggest a role for some other non-DAT target for SRI-31142 effects.

\section{Acknowledgments}

We thank Dr. Murray Stackhouse in the Toxicology and Pathology Services Division of Southern Research for providing the pharmacokinetic data on SRI-31142. 


\section{Authorship Contributions}

Participated in research design: Moerke, Ananthan, Banks, Eltit, Freitas, Johnson, Steele, and Negus.

Conducted experiments: Moerke, Ananthan, Eltit, Freitas,

Johnson, and Steele.

Contributed new reagents or analytic tools: Ananthan and Saini.

Performed data analysis: Moerke, Ananthan, Eltit, Freitas, Johnson, and Steele.

Wrote or contributed to the writing of the manuscript: Moerke, Ananthan, Banks, Eltit, Freitas, Johnson, Saini, Steele, Negus.

\section{References}

Battisti UM, Sitta R, Harris A, Sakloth F, Walther D, Ruchala I, Negus SS, Baumann MH, Glennon RA, and Eltit JM (2018) Effects of N-alkyl-4-methylamphetamine optical isomers on plasma membrane monoamine transporters and abuse-related behavior. ACS Chem Neurosci 9:1829-1839.

Bauer CT, Banks ML, Blough BE, and Negus SS (2013) Use of intracranial selfstimulation to evaluate abuse-related and abuse-limiting effects of monoamine releasers in rats. Br J Pharmacol 168:850-862.

Bauer CT, Banks ML, and Negus SS (2014) The effect of chronic amphetamine treatment on cocaine-induced facilitation of intracranial self-stimulation in rats. Psychopharmacology (Berl) 231:2461-2470.

Baumann MH, Char GU, De Costa BR, Rice KC, and Rothman RB (1994) GBR12909 attenuates cocaine-induced activation of mesolimbic dopamine neurons in the rat. $J$ Pharmacol Exp Ther 271:1216-1222.

Besnard J, Ruda GF, Setola V, Abecassis K, Rodriguiz RM, Huang XP, Norval S, Sassano MF, Shin AI, Webster LA, et al. (2012) Automated design of ligands to polypharmacological profiles. Nature 492:215-220.

Bonano JS, Glennon RA, De Felice LJ, Banks ML, and Negus SS (2014a) Abuse-related and abuse-limiting effects of methcathinone and the synthetic "bath salts" cathinone analogs methylenedioxypyrovalerone (MDPV), methylone and mephedrone on intracranial self-stimulation in rats. Psychopharmacology (Berl) 231:199-207.

Bonano JS, Runyon SP, Hassler C, Glennon RA, and Stevens Negus S (2014b) Effects of the neuropeptide S receptor antagonist RTI-118 on abuse-related facilitation of intracranial self-stimulation produced by cocaine and methylenedioxypyrovalerone (MDPV) in rats. Eur J Pharmacol 743:98-105.

Cameron KN, Solis E Jr, Ruchala I, De Felice LJ, and Eltit JM (2015) Amphetamine activates calcium channels through dopamine transporter-mediated depolarization. Cell Calcium 58:457-466.

Carlezon WA Jr and Chartoff EH (2007) Intracranial self-stimulation (ICSS) in rodents to study the neurobiology of motivation. Nat Protoc 2:2987-2995.

Czoty PW, Ginsburg BC, and Howell LL (2002) Serotonergic attenuation of the reinforcing and neurochemical effects of cocaine in squirrel monkeys. J Pharmacol Exp Ther 300:831-837.

Di Chiara G and Imperato A (1988) Drugs abused by humans preferentially increase synaptic dopamine concentrations in the mesolimbic system of freely moving rats. Proc Natl Acad Sci USA 85:5274-5278.

Glowa JR, Wojnicki FHE, Matecka D, Rice KC, and Rothman RB (1995) Effects of dopamine reuptake inhibitors on food- and cocaine-maintained responding: II. Comparisons with other drugs and repeated administrations. Exp Clin Psychopharmacol 3: $232-239$.

Johnson AR, Banks ML, Selley DE, and Negus SS (2018) Amphetamine maintenance differentially modulates effects of cocaine, methylenedioxypyrovalerone (MDPV), and methamphetamine on intracranial self-stimulation and nucleus accumbens dopamine in rats. Neuropsychopharmacology 43:1753-1762

Kivell B, Uzelac Z, Sundaramurthy S, Rajamanickam J, Ewald A, Chefer V, Jaligam V, Bolan E, Simonson B, Annamalai B, et al. (2014) Salvinorin A regulates dopamine transporter function via a kappa opioid receptor and ERK1/2-dependent mechanism. Neuropharmacology 86:228-240.

Lazenka MF and Negus SS (2017) Oral modafinil facilitates intracranial self-stimulation in rats: comparison with methylphenidate. Behav Pharmacol 28:318-322

Lindsey KP, Wilcox KM, Votaw JR, Goodman MM, Plisson C, Carroll FI, Rice KC, and Howell LL (2004) Effects of dopamine transporter inhibitors on cocaine selfadministration in rhesus monkeys: relationship to transporter occupancy determined by positron emission tomography neuroimaging. J Pharmacol Exp Ther 309:959-969.

Maisonneuve IM, Archer S, and Glick SD (1994) U50,488, a kappa opioid receptor agonist, attenuates cocaine-induced increases in extracellular dopamine in the nucleus accumbens of rats. Neurosci Lett 181:57-60.

Matecka D, Rothman RB, Radesca L, de Costa BR, Dersch CM, Partilla JS, Pert A Glowa JR, Wojnicki FH, and Rice KC (1996) Development of novel, potent, and selective dopamine reuptake inhibitors through alteration of the piperazine ring of 1-[2-(diphenylmethoxy)ethyl]-and 1-[2-[bis(4-fluorophenyl)methoxy]ethyl]4-(3-phenylpropyl)piperazines (GBR 12935 and GBR 12909). J Med Chem 39 $4704-4716$.

Negus SS and Henningfield J (2015) Agonist medications for the treatment of cocaine use disorder. Neuropsychopharmacology 40:1815-1825.

Negus SS, Mello NK, Kimmel HL, Howell LL, and Carroll FI (2009) Effects of the monoamine uptake inhibitors RTI-112 and RTI-113 on cocaine- and foodmaintained responding in rhesus monkeys. Pharmacol Biochem Behav 91 333-338.

Negus SS and Miller LL (2014) Intracranial self-stimulation to evaluate abuse potential of drugs. Pharmacol Rev 66:869-917.

Pariser JJ, Partilla JS, Dersch CM, Ananthan S, and Rothman RB (2008) Studies of the biogenic amine transporters. 12. Identification of novel partial inhibitors of amphetamine-induced dopamine release. J Pharmacol Exp Ther 326: $286-295$.

Paxinos G and Watson C (2007) The Rat Brain in Stereotaxic Coordinates, 6th ed, Academic Press, Cambridge, MA.

Reith ME, Blough BE, Hong WC, Jones KT, Schmitt KC, Baumann MH, Partilla JS, Rothman RB, and Katz JL (2015) Behavioral, biological, and chemical perspectives on atypical agents targeting the dopamine transporter. Drug Alcohol Depend 147: $1-19$

Rosenberg MB, Carroll FI, and Negus SS (2013) Effects of monoamine reuptake inhibitors in assays of acute pain-stimulated and pain-depressed behavior in rats. $J$ Pain 14:246-259.

Rothman RB, Ananthan S, Partilla JS, Saini SK, Moukha-Chafiq O, Pathak V, and Baumann MH (2015) Studies of the biogenic amine transporters 15. Identification of novel allosteric dopamine transporter ligands with nanomolar potency. $J$ Pharmacol Exp Ther 353:529-538.

Rothman RB and Baumann MH (2006) Balance between dopamine and serotonin release modulates behavioral effects of amphetamine-type drugs. Ann N Y Acad Sci 1074:245-260.

Rothman RB, Baumann MH, Prisinzano TE, and Newman AH (2008) Dopamine transport inhibitors based on GBR12909 and benztropine as potential medications to treat cocaine addiction. Biochem Pharmacol 75:2-16.

Ruchala I, Cabra V, Solis E Jr, Glennon RA, De Felice LJ, and Eltit JM (2014) Electrical coupling between the human serotonin transporter and voltage-gated $\mathrm{Ca}(2+)$ channels. Cell Calcium 56:25-33.

Sakloth F and Negus SS (2018) Naltrexone maintenance fails to alter amphetamine effects on intracranial self-stimulation in rats. Exp Clin Psychopharmacol 26: 195-204.

Schindler CW, Thorndike EB, Goldberg SR, Lehner KR, Cozzi NV, Brandt SD, and Baumann $\mathrm{MH}$ (2016) Reinforcing and neurochemical effects of the "bath salts" constituents 3,4-methylenedioxypyrovalerone (MDPV) and 3,4-methylenedioxy-Nmethylcathinone (methylone) in male rats. Psychopharmacology (Berl) 233: 1981-1990.

Solis E Jr, Partilla JS, Sakloth F, Ruchala I, Schwienteck KL, De Felice LJ, Eltit JM, Glennon RA, Negus SS, and Baumann MH (2017) N-alkylated analogs of 4-methylamphetamine (4-MA) differentially affect monoamine transporters and abuse liability. Neuropsychopharmacology 42:1950-1961.

Solis E Jr, Zdravkovic I, Tomlinson ID, Noskov SY, Rosenthal SJ, and De Felice LJ (2012) 4-(4-(dimethylamino)phenyl)-1-methylpyridinium (APP+) is a fluorescent substrate for the human serotonin transporter. J Biol Chem 287: 8852-8863.

Suyama JA, Sakloth F, Kolanos R, Glennon RA, Lazenka MF, Negus SS, and Banks ML (2016) Abuse-related neurochemical effects of para-substituted methcathinone analogs in rats: microdialysis studies of nucleus accumbens dopamine and serotonin. J Pharmacol Exp Ther 356:182-190.

Tanda G, Newman AH, and Katz JL (2009) Discovery of drugs to treat cocaine dependence: behavioral and neurochemical effects of atypical dopamine transport inhibitors. Adv Pharmacol 57:253-289.

Walsh SL, Geter-Douglas B, Strain EC, and Bigelow GE (2001) Enadoline and butorphanol: evaluation of kappa-agonists on cocaine pharmacodynamics and cocaine self-administration in humans. J Pharmacol Exp Ther 299:147-158.

Wise RA (1996) Addictive drugs and brain stimulation reward. Annu Rev Neurosci 19:319-340.

Zanettini C, Wilkinson DS, and Katz JL (2018) Behavioral economic analysis of the effects of N-substituted benztropine analogs on cocaine self-administration in rats. Psychopharmacology (Berl) 235:47-58.

Address correspondence to: Dr. S. Stevens Negus, Department of Pharmacology and Toxicology, Virginia Commonwealth University, 410 North 12th Street, Richmond, VA 23298. E-mail: sidney.negus@vcuhealth.org 